\title{
NASA puts the squeeze on low-cost missions
}

Washington. Concern is growing among scientists preparing to submit ideas for lowcost planetary missions to the US National Aeronautics and Space Administration (NASA) that even more stringent costlimits have been introduced by the agency less than a month before the call for proposals is scheduled to go out.

The 'Discovery' line of planetary missions was introduced by NASA two years ago as a way of bringing down the cost of Solar System exploration, increasing the flight rate and taking advantage of new spacecraft technology. According to the programme guidelines, individual missions must cost no more than $\$ 150$ million each, take no longer than three years to develop, and be small enough to fly on a Delta rocket.

But a recent letter to the planetary research community from Wesley Huntress, NASA's associate administrator for space science, implies that missions in the $\$ 100$ million range and lower stand a better chance of being selected. It also implies that scientists should design their spacecraft for launch by cheaper, less powerful rockets.

"Given the agency projections for a denext several years it is not possible to be confident concerning the annual funding level that might finally result from the 1996 budget process", wrote Huntress.

And he chided the planetary science community for its tendency to design Discovery proposals to "fill the bucket", with crease in space science funding over the

the result that the majority of ideas for Discovery missions were at the $\$ 150$ million mark.

He estimated that future budgets for the programme would be $\$ 100$ million, and said the frequently repeated goal of one launch a year will not be possible if every proposal costs close to $\$ 150$ million. "Recent experience and studies have shown that Discovery missions with development costs less than $\$ 100$ million can produce valuable scientific data," Huntress added.

Huntress denies that the letter is intended to indicate an unofficial ceiling for proposed missions of $\$ 100$ million. He insists that NASA is not ruling out $\$ 150$ million missions, but is trying to introduce "budget flexibility" to the programme.

But many space scientists see the letter as an indication that the Discovery programme is already on shaky ground, even before the first two missions - the Near-Earth Asteroid Rendezvous (NEAR) and a small Mars lander called MESUR Pathfinder - make it to the launch pad.

Joseph Veverka of Cornell University, who has had two Discovery concepts approved by NASA for further study, called the letter "extremely worrisome", because it decreased the commitment of resources and increased the number of requirements.

Huntress also told scientists that total cost will in future be a factor in evaluating which projects get funded with low launch and mission operations costs receiving higher

\section{Scientists urge peer review on historians}

Washington. The Federation of American Scientists (FAS) is urging book publishers to experiment with an equivalent of scientific peer review to avoid a repetition of the character assassination which, it claims, was carried out on physicists Robert Oppenheimer, Enrico Fermi, Leo Szilard and Niels Bohr in a book published earlier this year.

In an extensive review of the circumstances surrounding the memoir Special Tasks by ex-KGB agent Pavel Sudoplatov, written with American journalists Jerrold and

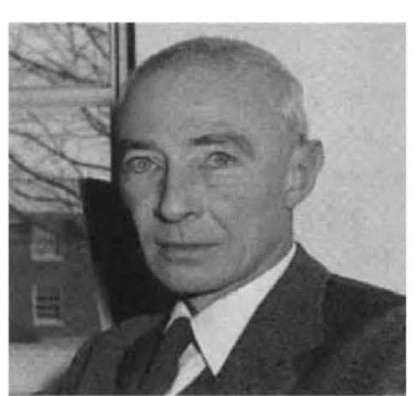

Oppenheimer: victim of new attacks.
Leona Schecter - the FAS says that the charges in the book have been widely discredited, and attacks the attitude of New York publishers Little-Brown as "shameless" (see Nature 368, 779; 1994).

The FAS, a respected, 3,000-strong liberal pressure group whose membership includes 40 Nobel prizewinners, calls on Gerald Levin, the chairman of Time-Warner which owns both LittleBrown and Time magazine, which published parts of the memoir, to apologize to the families of the scientists for charges which it describes as "widely denounced and unsubstantiated".

It urges publishers to check 'revelations' with expert historians, "perhaps under conditions of confidentiality to protect the news value of the disclosures." The FAS hopes publishers will be prepared to do this because they have been embarrassed by the publicity surrounding Special Tasks.

Sales of the book are said to have been weak after scathing reviews. But the FAS is concerned that a flood of KGB memoirs is now on the way, and that many of them are likely to contain extravagant claims in order to boost sales in the West. marks. Many scientists proposing Discovery missions had understood from the original guidelines that a Delta rocket would be furnished at no extra cost by NASA, and that launch costs were therefore irrelevant.

Paul Spudis, a scientist with the Lunar and Planetary Institute in Houston, whose proposal for a Mercury fly-by mission was also chosen for further study, is among those whose project might be axed under the new guidelines. "If they were to down-size the vehicles, we'd be in trouble," he says.

Some researchers have been angered by Huntress' apparent implication that it is irresponsible to propose missions at or near the $\$ 150$ million mark, arguing that it was NASA, not they, who set that target in the first place. According to Veverka the original cost guidelines were "pretty reasonable" because they allowed a diversity of Solar System targets to be reached, including mainbelt asteroids, Venus and Mars.

If the missions are limited to $\$ 100$ million, it will limit the number of targets says Joseph Burns, head of a National Academy of Sciences committee on planetary science that is due to publish a report on small missions later this year.

Not all scientists think that reducing the price of Discovery missions would necessarily be a bad idea. Spudis, who was on the team for the Pentagon's recent Clementine Moon mission, says he supports the idea of selecting the cheapest possible missions if they can return good science.

But changing the rules on mission cost after years of quoting the $\$ 150$ million figure amounts to a "last-minute trap door" just as scientists are about to submit their proposals. Spudis says that a budget guessing game would leave him questioning NASA's commitment to the programme.

Burns agrees that it would be better for the agency to simply come out and set a lower ceiling instead of being vague.

Huntress defends the variable pricing scheme, saying that NASA has always made it clear it was looking for a spectrum of costs in mission. But he also acknowledged that the space science community is "very, very sensitized" to news of budgetary cuts.

Many scientists in turn say they sympathize with Huntress' difficulties in trying to defend space science at a time when the agency's budget is being slashed, while the space station is being protected for political reasons. Some even believe that the cost of planetary missions will have to come down even further, to well below Discovery levels, if the programme is to survive.

But with only three missions - the Cassini Saturn probe, NEAR, and MESUR Pathfinder - currently in the funding pipeline, Discovery is, for planetary scientists, about the only game in town.

Tony Reichhardt 